\title{
UNILATERAL OPEN LIP SCHIZENCEPHALY ASSOCIATED WITH PARTIAL AGENESIS OF CORPUS CALLOSUM.
}

N. Bharadwaj, D. Eshwara Chary, K Bhaskara Narayan, Vivekanand
1. Post Graduate. Department of Paediatrics, M.N. R. Medical College \& Hospital.
2. HOD. Department of Paediatrics, M.N. R. Medical College \& Hospital.
3. Tutor. Department of Radiology, DMRD. M.N. R. Medical College.
4. Associate Professor. Department of Pathology, Osmania Medical College.

\section{CORRESPONDING AUTHOR:}

N. Bharadwaj, Flat no 204, Venkatadri apartments, Svrs complex, Saroornagar, Hyderabad, Andhrapradesh-500035.

E-mail: namalabharadwaj@gmail.com

ABSTRACT: Schizencephaly is a rare developmental disorder of congenital cerebral malformation. We bring to your attention the case study of a 5 year old female child reported with focal seizures and right hemiparesis since 5 months of her age. Her parents gave history of birth asphyxia and global developmental delay. On examination decreased muscle bulk, increased muscle tone, decreased muscle power, exaggerated tendon reflexes on right upper and lower limbs, and up going plantars on right lower limb with hemiplegic gait was observed. Magnetic resonance imaging (MRI) scan revealed open lip schizencephaly of left parietal cortex and partial agenesis of corpus callosum.

KEY WORDS: Schizencephaly, seizures, hemiparesis, corpus callosum.

MeSH TERMS: Schizencephaly, Agenesis of corpus callosum, cerebral cortex, Female, Seizure, Paresis, Reflex, MRI scans, cortical dysplasia.

INTRODUCTION: Schizencephaly is an uncommon congenital cerebral malformation that involves cerebral mantle and consists of a cleft that extends through the entire cerebral hemisphere from the lateral ventricle to the cerebral cortex. Schizencephaly has a prevalence of $1.48 / 100000$ births (1). It is a disorder with heterogeneous origin many of which are vascular disruptive in origin (2). They may present with intractable seizures and variable developmental delay (3). A large number of patients have associated brain abnormalities which may account for the severity of some cases. These include agenesis of the septum pellucidum, focal cortical dysplasia, and dysgenesis of the corpus callosum (4).

The corpus callosum is a wide, flat bundle of neural fibers beneath the cortex which connects the left and right cerebral hemispheres and facilitates interhemispheric communication. It is the largest white matter structure in the brain, consisting of 200-250 million contra lateral axonal projections. Agenesis of the corpus callosum is a rare congenital disorder. It occurs when the corpus callosum fails to develop normally, typically during pregnancy. This can be complete (absence of all components) or partial (presence of a short remnant) (5). Partial agenesis of the corpus callosum results from an arrest of growth which occurs between 12 and 18 weeks of gestation (6).

CASE REPORT: A 5 year old female child was brought to our hospital by her father. The father reported that his daughter has been experiencing weakness in her right hand and leg since 5 
months of her age. For the past 7 days, she has seizures in her right hand, each lasting for about five minutes and around 3 to 5 episodes per day. There is no history of loss of her consciousness during seizure episodes. She had been taken to local hospital and treated as a case of epilepsy. Child was referred to our hospital for further investigation. After prescribing antiepileptics to the patient seizures subsided. In the past similar episodes of seizures were noticed by her parents. The birth history consisted of delivery at full term gestation by vaginal route at a tertiary care hospital. The child did not cry soon after birth and was admitted in NICU as a case of birth asphyxia. There is no history of consanguineous marriage. On physical examination, the child had no dysmorphism of the face, the anterior fontanelle and sutures were normal. There was a global delay in developmental milestones. Anthropometric measurements and vitals were within normal limits. Examination revealed decreased muscle bulk, increased tone, decreased power, exaggerated tendon reflexes in right upper and lower limbs, and up going plantars in right lower limb with a hemiplegic gait. Routine hematological and urine examination were unremarkable. MRI scan revealed morphology in favor of open lip schizencephaly of left parietal cortex (Figure 1) and partial agenesis of corpus callosum (Figure 2).

DISCUSSION: Schizencephaly appears as a cleft filled with cerebrospinal fluid and extending medially from the subarachnoid space into the lateral ventricle. The wall of the cleft is lined with dysmorphic gray matter. The gray matter sometimes extends into the lateral ventricle in the form of subependymal heterotopias. The cleft may be small or large, unilateral or bilateral. The anomaly may be of the open-lip or closed-lip type. Closed-lip schizencephaly is characterized by gray matter-lined lips, which are in contact with each other (type 1). Open-lip schizencephaly has separated lips and a cleft of CSF extending to the underlying ventricles (type 2) (7).Toxic exposure, viral infections, genetic factors, vascular, familial, or metabolic involvement have been suggested to explain the complex cause of schizencephaly (8). Loss-of-function mutations in EMX2 have been described in individuals with the radiological diagnosis of schizencephaly (9). Clinical manifestations may be variable i.e. asymptomatic to those with epilepsy and neurodevelopment problems. MRI is the imaging modality of choice because of its superior differentiation of gray matter. Identification of gray matter lining the cleft is the pathognomonic finding (10).Treatment consists of commencing antiepileptic therapy and physiotherapy. Surgical treatment has been reported in cases of medically intractable epilepsy, but it is rarely considered (11).

Agenesis of the corpus callosum is one of the most frequent malformations in brain with a reported incidence ranging between 0.5 and 70 in 10, 000 (12). Complete and partial agenesis of corpus callosum can result from genetic, infectious, vascular, or toxic causes (13). Clinical symptoms of corpus callosum agenesis are quite different, the most common being macrocephaly, facial dysmorphy, in combination with different levels of mental retardation, epileptic seizures, vision and other nerve impairments (14).

We intend to report this rare case because of the complex clinical presentation with a combination of congenital malformations (schizencephaly, and dysgenesis of corpus callosum) in the same child.

CONCLUSION: Schizencephaly is a rare congenital disorder of cerebral cortical development which mainly manifests as two types i.e. open type and closed type. Most of the cases present with seizures and developmental delay. It may be associated with malformations like cortical 
dysplasia and dysgenesis of corpus callosum. These malformations can be clearly visualized on the MRI scans.

\section{REFRENCES:}

1. D. T. HOWE, J. RANKIN and E. S. DRAPER. Schizencephaly prevalence, prenatal diagnosis and clues to etiology: a register-based study. Ultrasound Obstet Gynecol 2012; 39: 75-82.

2. A. James Barkovich, Renzo Guerrini, Ruben I. Kuzniecky, Graeme D. Jackson and William B. Dobyns. A developmental and genetic classification for malformations of cortical development: update 2012. Brain 2012: 135; 1348-1369.

3. Srikanth SG, Jayakumar PN, Vasudev MK. Open and minimally open lips schizencephaly. Neurol India 2000; 48:155.

4. Richard J. Leventer, MBBS, PhD; Renzo Guerrini, MD; William B. Dobyns,MD. Malformations of cortical development and epilepsy. Dialogues Clin Neurosci. 2008; 10:47-62.

5. S. SANTO, F. D'ANTONIO, T. HOMFRAY, P. RICH, G. PILU, A. BHIDE et al. Counseling in fetal medicine: agenesis of the corpus callosum. Ultrasound Obstet Gynecol 2012; 40: 513-521.

6. T. GHI, A. CARLETTI, E. CONTRO, E. CERA, P. FALCO, G. TAGLiAVINI et al. Prenatal diagnosis and outcome of partial agenesis and hypoplasia of the corpus callosum. Ultrasound Obstet Gynecol 2010; 35: 35-41

7. A.A.K. Abdel Razek, A.Y. Kandell, L.G. Elsorogy, A. Elmongy, A.A. Basett. Disorders of Cortical Formation: MR Imaging Features. AJNR Am J Neuroradiol 30:4 -11.

8. Utku Senol, Kamil Karaali, Berrin Aktekin, Saim Yilmaz, and Timur Sindel. Dizygotic Twins with Schizencephaly and Focal Cortical Dysplasia. AJNR Am J Neuroradiol 21:15201521, September 2000.

9. Keith L. Ligon, Yann Echelard, Stavroula Assimacopoulos, Paul S. Danielian, Sovann Kaing, Elizabeth A. Grove et al. Loss of Emx2 function leads to ectopic expression of Wnt1 in the developing telencephalon and cortical dysplasia. Development 130, 2275-2287.

10. P. V. Chaitanya Varma, Y. Ramesh Bhat, and Sonia Bhatt. Unilateral open-lip schizencephaly: A rare cause of infantile hemiparesis. J Pediatr Neurosci. 2012 Sep-Dec; $7(3): 234-235$.

11. Celi Santos Andrade, Claudia da Costa Leite. Malformations of cortical development. Arq Neuropsiquiatr 2011;69(1):130-138.

12. Chayim Can Schell-Apacik, Kristina Wagner, Moritz Bihler, Birgit Ertl-Wagner, Uwe Heinrich, Eva Klopocki et a. Agenesis and Dysgenesis of the Corpus Callosum: Clinical, Genetic and Neuroimaging Findings in a Series of 41 Patients. Am J Med Genet A. 2008 October 1; 146 A(19): 2501-2511.

13. Lynn K. Paul. Developmental malformation of the corpus callosum: a review of typical callosal development and examples of developmental disorders with callosal involvement. J Neurodev Disord. 2011 Mar; 3(1):3-27

14. Dubravka Šepić-Grahovac, Antonija Ružić Baršić, Klementina Ružić, Tanja Grahovac3 \& Elizabeta Dadić-Hero. NEUROLOGICAL AND PSYCHIATRIC ASPECTS OF CORPUS CALLOSUM GENESIS. Psychiatria Danubina, 2010; Vol. 22, No. 2, pp 282-285. 


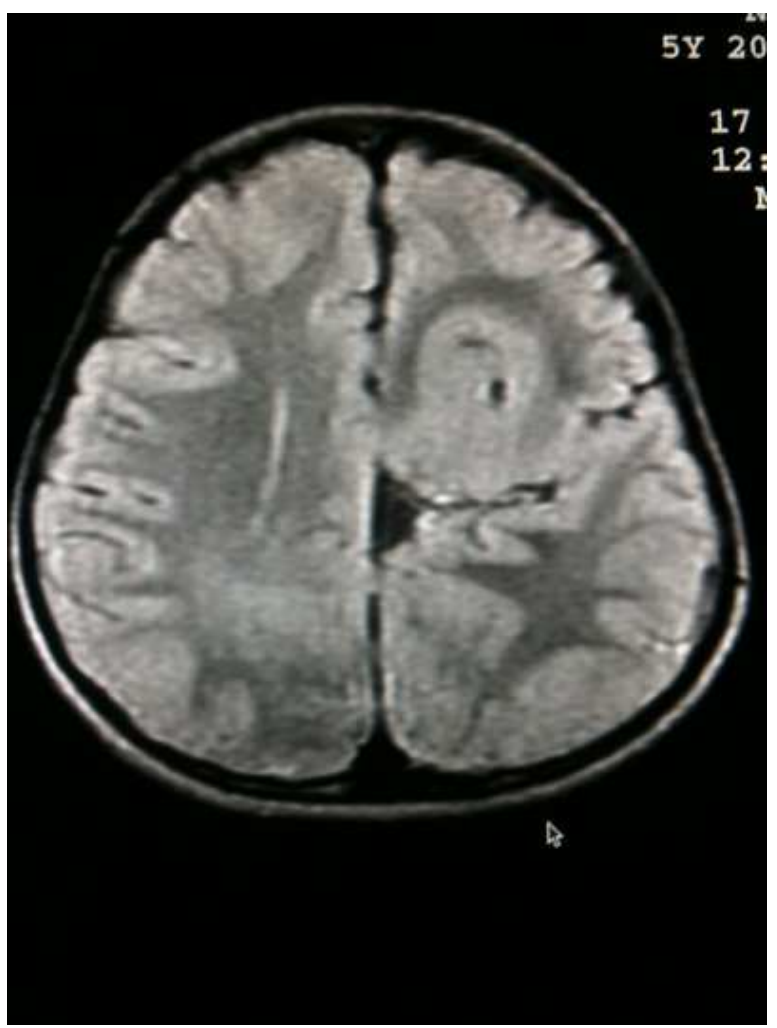

Figure 1: MRI scan showing open lip Schizencephaly of left parietal cortex.

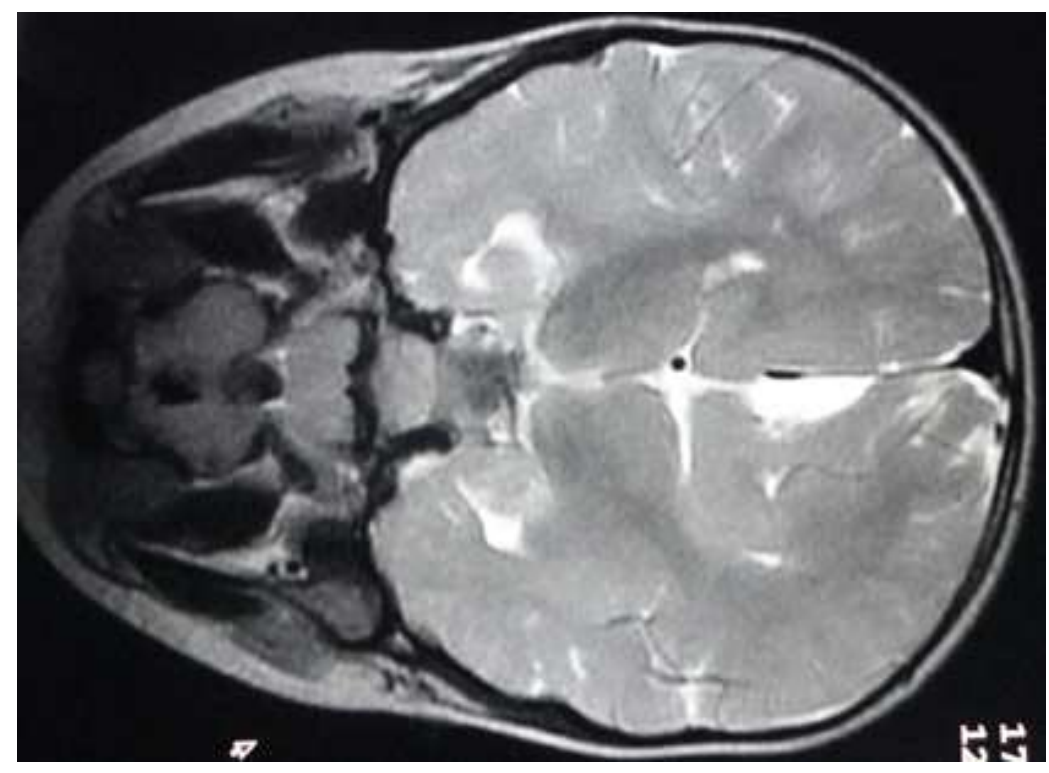

Figure 2: MRI scan showing partial agenesis of corpus callosum. 